LAPORAN KASUS

\title{
Keberhasilan Setelah Henti Jantung selama Torakotomi Emergensi disebabkan Luka Penetrasi Trauma Torak pada Kondisi Dengan Keterbatasan Fasilitas
}

\section{Survive After Cardiac Arrest During Emergency Thoracotomy Due To Penetrating Thoracic Trauma In Resource Limited Settings}

\author{
Mumya Camary $\square^{*}$, Akhyar H Nasution*, Hasanul Arifin* \\ *Departemen Anestesiologi dan Terapi Intensif Fakultas Kedokteran Universitas Sumatera Utara, Rumah Sakit Haji Adam Malik \\ Medan \\ $\triangle$ Korespondensi/ correspondence: dicamary_007@yahoo.com
}

\section{ABSTRACT}

Background: An emergency thoracotomy (sometimes referred to as a resuscitative thoracotomy) is a thoracotomy typically done in order to resuscitate a person who has been severely injured after sustaining a severe trauma involving the thoracic cavity. Cardiac arrest can occur durante procedure of emergency thoracotomy which need internal massage and defibrillation, A quick management with The combination of clinical foreknowledge, ability to spot changing clinical signs, and even-tempered surgical courage to perform simple but lifesaving procedures can bring about a profound difference in outcome for the chest injured patient even in resource limited settings.

Case: Male, 31 years old, predicted body weight $70 \mathrm{~kg}$ admitted to Haji Adam Malik Hospital with main complained stab wound on the left chest. Supine chest $x$-ray shown massive left-sided hemothorax. Chest wound was opened on the left antero lateral by surgeon and seen left lung collapse with estimated blood lost $2500 \mathrm{ml}$ are taken from the left hemithorax, surgeon make a decision to do sternotomy and then found Left internal mammary artery was torn and was ligated, found the right ventricle lacerated but no bleeding from the wound. Cardiac arrest occurs and the surgeon starts internal cardiac massage, continuing fluid resuscitation, 15 minutes after rescucitating cardiac arrest ECG shown VF, Internal defibrillation at 20 joules, ECG shown sinus tachycardia 145/min, after control bleeding, the operation procedure are done after chest drain insertion bilateral. The patient was shifted to surgical ICU for observation. Patient was stable and there were no complications in postoperative periode. Patient was discharged on 8 th postoperative day.

Summary: The decision to perform emergency thoracotomy involves careful evaluation of the scientific, ethical, social and economic issues. A quick management with The combination of clinical foreknowledge, ability to spot changing clinical 
signs, and even-tempered surgical courage to perform simple but lifesaving procedures can bring about a profound difference in outcome for the chest injured patient even in resource limited settings. Time saving is live saving.

Keywords: emergrncy thoracotomi, cardiac arrest.

\section{ABSTRAK}

Latar Belakang: Sebuah torakotomi darurat (kadang-kadang disebut sebagai torakotomi resusitasi) adalah torakotomi yang dilakukan untuk meresusitasi seseorang yang telah terluka parah setelah mengalami trauma berat pada rongga dada. Henti jantung dapat terjadi selama prosedur torakotomi yang memerlukan pijat jantung internal dan defibrilasi. Manajemen yang cepat dengan Kombinasi ramalan klinis, kemampuan untuk melihat perubahan tanda-tanda klinis, dan keberanian untuk melakukan prosedur bedah sederhana namun menyelamatkan nyawa dapat membawa perbedaan hasil bagi pasien luka dada bahkan di tempat dengan sumber daya terbatas.

Kasus: Laki-laki, 31 tahun, berat badan perkiraan $70 \mathrm{~kg}$ dirawat di Rumah Sakit Haji Adam Malik dengan keluhan luka tusuk di dada kiri. Pemrisaan ronsen dada menunjukkan hemothorax luas di sisi kiri. Dokter bedah membuka dada yang terkena luka tusuk dan terlihat kolaps paru dengan darah diperkirakan $2.500 \mathrm{ml}$ dari hemitoraks kiri, ahli bedah memutuskan untuk melakukan sternotomy dan kemudian menemukan robekan pada arteri mamaria interna kiri dan diligasi, ditemukan robek ventrikel kanan tetapi tidak ada pendarahan dari luka. Serangan jantung terjadi dan ahli bedah mulai pijat jantung internal dan resusitasi cairan, 15 menit setelahnya EKG menunjukkan VF, defibrilasi internal pada 20 joule, EKG menunjukkan sinus takikardia 145/min, setelah mengontrol perdarahan, prosedur operasi selesai dan dilakukan pemasangan selang dada. Pasien dipindahkan ke ICU untuk observasi. Pasien stabil dan tidak ada komplikasi pada pasca operasi . Pasien dipulangkan pada harike 8 pasca operasi.

Ringkasan: Keputusan untuk melakukan torakotomi darurat melibatkan evaluasi yang cermat di bidang ilmiah, isu-isu etika, sosial dan ekonomi. Manajemen yang cepat dengan Kombinasi ramalan klinis, kemampuan untuk melihat perubahan tanda-tanda klinis, dan keberanian untuk melakukan prosedur bedah sederhana namun menyelamatkan nyawa dapat membawa perbedaan hasil bagi pasien luka dada bahkan di tempat dengan sumber daya terbatasTabungan Waktu adalah tabungan hidup.

Kata kunci: torakotomi darurat, henti jantung 


\section{PENDAHULUAN}

Trauma torak sebagai penyebab satu dari setiap empat kematian akibat trauma di Amerika Utara. ${ }^{1,2}$ Distribusi cedera tidak berhubungan dengan anatomi pada segmen paru yang cedera namun secara langsung terkait dengan cedera pada dinding dada. Trauma toraks relatif umum terjadi pada $17 \%$ pasien dengan multiple trauma (Injury Severity Score $>15)$. Perdarahan ke alveoli dan kerusakan parenkim maksimal terjadi dalam 24 jam pertama setelah cedera, hipoksemia dan hiperkapnia puncaknya terjadi 72 jam setelah cedera.

Meskipun trauma toraks relatif umum terjadi, kejadian cedera dada terisolasi yang memerlukan tindakan torakotomi jumlahnya kecil. Sekitar $18 \%$ dari pasien membutuhkan pemasangan WSD dan sekitar 2,5\% yang memerlukan tindakan torakotomi. Mortalitas secara keseluruhan adalah sekitar 9\% dengan Glasgow Coma Scale skor yang rendah, usia yang tua, adanya luka tembus dada dan patah tulang panjang, fraktur lebih dari lima tulang rusuk, dan trauma pada hati dan cedera limpa menjadi prediktor independen terjadinya kematian. ${ }^{3}$

Manajemen segera trauma toraks harus mengikuti standar Advanced Trauma Life Support (ATLS) yang bertujuan untuk mengidentifikasi urutan cedera yang paling mengancam kehidupan diantara ancaman terhadap kehidupan.

\section{KASUS}

Laki-laki, 31 tahun, diperkirakan berat badan $70 \mathrm{~kg}$ datang ke Rumah Sakit Haji Adam Malik dengan keluhan utama luka tusuk di dada kiri. Pada pemeriksaan didapatkan pasien dalam keadaan sadar penuh. Kecepatan napas 30/min, tidak ada keluhan dari hemoptisis, hematemesis. Akral dingin dan pucat. Denyut nadi 130/min, teratur, dan tekanan darah 90/50 mm $\mathrm{Hg}$ dengan respon sementara terhadap resusitasi cairan. Tidak ada riwayat penyakit penting lainnya. Laboratorium dengan $\mathrm{Hb} 7,8$ dan hasil lainnya adalah dalam batas normal, EKG sinus takikardi, x-ray dada menunjukkan hemothorax sisi kiri yang masif.

Pasien dibawa ke ruang operasi. CVC dipasang pada subclavia kiri dan dua jalur I.V. line dengan bore besar pada kedua tangan, monitor $\mathrm{SpO} 2$ dan monitor EKG diterapkan. Didapatkan SpO2 100\% dengan udara bebas. Preload dengan kristaloid $1000 \mathrm{ml}, 100 \%$ O2 diberikan melalui facemask. Tekanan darah 80/60 mm Hg. Pasien diberikan Injeksi Sulfat Atropin 0,5 mg Kemudian pasien diinduksi dengan injeksi Ketamine $100 \mathrm{mg}$ dan Rocuronium 50 mg. Jalan nafas di jaga dengan dilakukan pemasangan endotrakeal tube dan. SBP adalah $90 \mathrm{~mm} \mathrm{Hg}$.

Luka dada dibuka di antero lateral kiri oleh dokter bedah dan paru kiri terlihat kolaps dengan perkiraan darah yang hilang $2.500 \mathrm{ml}$ yang diambil dari 


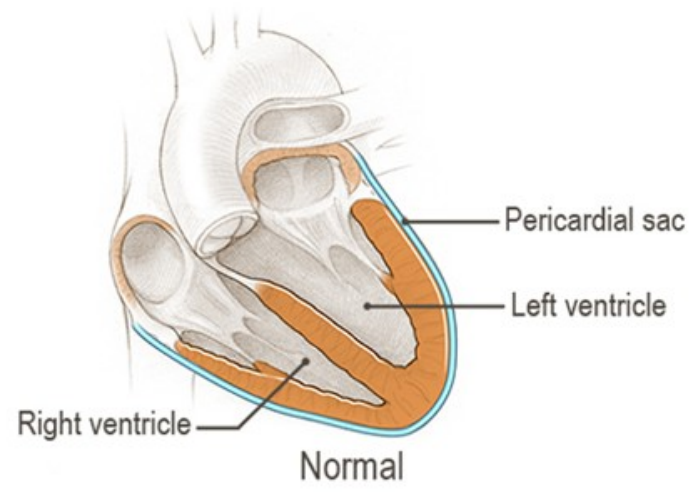

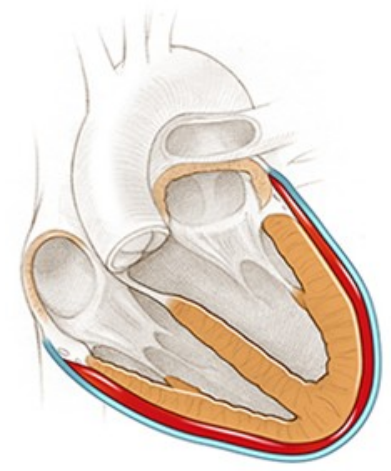

Moderate pericardial effusion

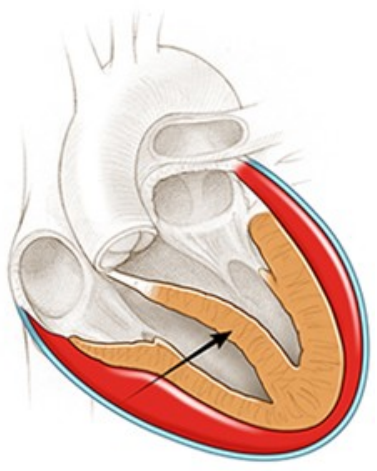

Ventricular collapse

Gambar 1.Tamponade Jantung

hemithorax kiri, ahli bedah membuat keputusan untuk melakukan sternotomy dan kemudian menemukan arteri mamaria interna kiri robek dan diputuskan untuk diligasi, ditemukan juga ventrikel kanan terdapat robek tetapi tidak terjadi pendarahan dari luka, SBP mulai jatuh ke $50 \mathrm{~mm} \mathrm{Hg}$ pada arteri brakialis, Inj. Norepinefrin dimulai pada tingkat 0,5 mikro gm/ menit dan dobutamin dimulai pada tingkat 5-6 mikro gm/menit. Pasien diberikan ventilasi dengan 100\% O2. Ahli bedah membuka perikardium melalui sayatan torakotomi kiri dan menemukan darah $150 \mathrm{ml}$. Segera setelah itu, henti jantung terjadi dan ahli bedah mulai melakukan pijat jantung internal, resusitasi cairan koloid dengan
$1000 \mathrm{ml}$, administrasi intracardiac dari epinefrin diberikan dengan dorongan yang cepat dan langsung disuntikkan ke dalam ruang dari ventrikel kiri setiap 3 menit, administrasi darah PRC $700 \mathrm{ml}$, natrium bikarbonat $75 \mathrm{meq} / \mathrm{L}$ dan Kalsium glukonase $20 \mathrm{ml}, 15$ menit setelah resusitas,pada EKG tampak VF, diputuskan untuk memberikan defibrilasi internal 20 joule, gambaran EKG menunjukkan sinus takikardia 145/min, setelah mengontrol perdarahan, prosedur operasi selesai setelah dilakukan pemasangan thorax drain bilateral dan pada akhir operasi denyut nadi 120/ minute reguler dan BP 100/70mm $\mathrm{Hg}$ tanpa dukungan inotropik.

Pasien dibawa ke ICU pasca bedah untuk 
observasi. Pasien stabil dan tidak ada komplikasi pada periode pasca operasi. Pasien dipulangkan 8 hari pasca operasi.

\section{PEMBAHASAN}

Ada 12 cedera toraks mematikan atau berpotensi mematikan yaitu obstruksi jalan napas, trauma pada aorta, tension pneumotoraks, ruptur tracheobronchial, open pneumotoraks, kontusio miokard, haemothorak masif, ruptur diafragma, flail chest, ruptur esofagus, tamponade jantung, dan kontusio paru.

\section{Obstruksi jalan napas}

Kerusakan pada laring atau trakea akibat dari trauma tumpul atau penetrasi dapat begitu parah hingga menyebabkan pasien meninggal di tempat kejadian. Dimana jalan napas terganggu maka tindakan untuk definitife airway diperlukan sebelum dilakukan tindakan anestesi umum. Intubasi dengan serat optik lebih sering dipraktekkan dibandingkan dengan laringoskopi langsung dengan anestesi lokal (awake intubation). ${ }^{4}$

\section{Tension Pneumothorax}

Diagnosis tension pneumothorax lebih kepada klinis daripada radiologis. Secara klinis, tension pneumothorax ditandai dengan bunyi nafas yang menghilang, perkusi yang hiperresonans, tidak ada gerakan dada pada sisi yang diduga cedera, deviasi trakea ke sisi terluka, vena leher yang terisi penuh (tidak dapat dilihat jika pasien hipovolemik), dispnea berat, takikardi dan hipotensi

Dekompresi thorax segera diperlukan dengan cara menggunakan kanula yang memiliki bore besar. Tindakan ini mendekompresi dada dan memungkinkan mediastinum untuk kembali ke posisi normal. Pemasangan Thorax drainage diperlukan dimana tension pneumotorax terjadi selama anestesi, dimana ventilasi mekanis akan menjadi sulit dikarenakan meningkatnya tekanan intra-toraks. Dalam mode pressure control pada ventilasi akan ada penurunan progresif dalam volume tidal dan gambaran jejak obstruksi pada end tidal CO2. Mode Volume kontrol akan ada peningkatan pesat dalam tekanan puncak jalan nafas dan ventilator mungkin gagal untuk melakukan siklus ventilasi. Dekompresi dengan jarum kurang efektif dalam mengurangi tekanan yang timbul selama ventilasi tekanan positif karena tidal volume setiap pemberian napas jauh lebih besar daripada volume yang mampu didekompresi melalui lubang jarum dekompresi. Pada pasien elektif dengan simple pneumotorax, maka pemasangan thorax drainage harus dilakukan sebelum tindakan anestesi. ${ }^{5}$

\section{Pneumotoraks Terbuka}

Setiap luka penetrans pada dinding dada yang besarnya lebih dari $2 / 3$ trakea memungkinkan udara untuk lebih mudah lewat melalui luka daripada saluran napas normal. Hal ini menyebabkan 
meningkatnya shunt intrapulmonal, penurunan aliran balik vena dan progresif hipoksemia dan hiperkapnia. Intubasi dan ventilasi tekanan positif dapat menyelesaikan masalah ini secara cepat. Pertolongan pertama yang dapat diberikan berupa pemberian oksigen, penutupan luka dan insersi chest drain. Torakotomi umumnya tidak diperlukan kecuali terdapat luka yang sangat besar ${ }^{6}$.

\section{Haemotoraks Masif}

Setiap haemotoraks yang terjadi pada orang dewasa mungkin mengalami kehilangan darah sebanyak 1,5 liter yang berasal dari pembuluh darah interkostal, arteri paru atau vena, avulsi pembuluh mediastinal atau cedera jantung penetrasi. Haemotoraks massif dapat menyerupai pneumotoraks ventil tetapi pada perkusi didapati beda bukan hipersonor. Torakotomi dan anestesi pada satu paru dibutuhkan yang kemudian dapat dipasang pipa lumen ganda pada kondisi yang telah terkontrol. Pemasangan abocath ukuran besar sangat diperlukan sebelum dilakukan insersi chest drain; Torakotomi dilakukan bila drainase lebih dari $250 \mathrm{ml}$ per jam atau status fisiologis dari pasien terus memburuk meskipun dilakukan penggantian cairan. Luka tembus medial dari garis putting pada bagian anterior atau medial dari scapula pada bagian posterior sangat berbahaya karena insiden cedera ke jantung, pembuluh darah besar, atau hilus lebih besar. ${ }^{7}$

\section{Tamponade Jantung}

Hal ini paling sering terjadi pada luka tembus. Volume ruang pericardial sekitar jantung sangat kecil dan kantong pericardial berserat dan relative tidak dapat teregang. Ketika darah terakumulasi di sekitar jantung, aliran balik vena menurun akibat kompresi atrial dan curah jantung menurun. Diagnosis sangat sulit ditegakkan dan dua dari trias Beck's - peningkatan TVJ dan muffled heart sound, sulit didapatkan dan tanda ketiga, hipotensi tidak spesifik. Pulsus paradoksus dapat ditemukan pada kondisi lain tetapi tanda Kussmaul's, peningkatan TVJ pada saat inspirasi selama bernapas spontan dapat digunakan untuk mendiagnosa. Ekokardiografi memberikan diagnosa definitif. Aspirasi 15-20 ml darah dari perikardium dapat menyebabkan peningkatan langsung curah jantung. Operasi perikardotomi biasanya menggunakan anestesi dengan endotrakeal lumen tunggal. Pemantauan tekanan vena sentral wajib dilakukan untuk mendiagnosa kekambuhan tamponade pasca operasi. ${ }^{8}$

\section{Anestesi untuk Torakotomi Resusitatif}

Cedera tembus pada jantung dapat menyebabkan henti jantung secara tibatiba. Pada kasus tertentu, torakotomi di IGD akan memungkinkan kontrol perdarahan dari jantung dan resusitasi cairan dan jantung yang efektif dapat terjadi. Intubasi trakea dilakukan dengan pipa lumen tunggal dan ventilasi dengan 
oksigen $100 \%$. Pasien yang henti jantung karena trauma tidak memerlukan induksi anestesi sebelum intubasi dan torakotomi. Pasien yang sadar tetapi hipotensi memerlukan penanganan yang berbeda. Induksi anestesi dapat menyebabkan penurunan tekanan darah yang drastis jadi harus berhati-hati dalam pemilihan agen induksi. Ketamin dan atau opoid (fentanil atau alfentanil) lebih dianjurkan. Anestesi dapat dipertahankan secara intravena melalui infus atau bolus. Obat pelumpuh otot harus dipertahankan sepanjang tindakan operasi berlangsung. Penanganan pneumotoraks ventil harus dilakukan secepat mungkin dengan torakotomi bilateral. Pneumotoraks ventil bilateral mungkin terjadi dan tanda klasiknya mungkin tidak tampak. Jadi, pada setiap kasus henti jantung secara traumatic harus dianggap karena pneumotoraks ventil. Kelebihan torakotomi bilateral adalah untuk mengidentifikasi dimana adanya haemorragik masif dan pada sisi dada yang mana terdapat luka yang menjadi luka mayor. Ini akan menentukan tempat insisi yang pertama pada torakotomi. Penanganan hemorragik toraks masif adalah kontrol perdarahan, bukan terapi cairan intra vena. Terapi cairan sebelum control perdarahan dapat memperparah hasil pada trauma toraks penetrative, jika tidak ada respon terhadap terapi cairan sebanyak $500 \mathrm{ml}$, pemberian cairan harus dihentikan sampai perdarahan benar-benar terkontrol. Setelah perdarahan terkontrol pasien akan memerlukan koreksi hipovolemia secara cepat untuk mengembalikan preload dan perfusi pada organ non vital. Pasien akan merasa dingin dan terjadi gangguan koagulasi yang lebih parah. Darah dan komponen terapi harus dihangatkan dan segara diberikan setelah perdarahan terkontrol. Defibrilasi internal mungkin diperlukan dan dukungan inotropik juga diperlukan setelah perdarahan terkontrol. $^{9}$

Pada kasus ini dilakukan torakotomi segera bersamaaan dengan dilakukannya kontrol perdarahan dari jantung dan resusitasi cairan yang efektif. Intubasi trakea dilakukan dengan pipa lumen tunggal dan ventilasi dengan oksigen 100\%. Pasien diinduksi dengan ketamin. Anestesi dipertahankan secara intravena melalui infus atau bolus. Obat pelumpuh otot rocuronium dipertahankan sepanjang tindakan operasi berlangsung. Penanganan hemorragik toraks masif adalah kontrol perdarahan, bukan terapi cairan intra vena. Terapi cairan sebelum control perdarahan dapat memperparah hasil pada trauma toraks penetrative, jika tidak ada respon terhadap terapi cairan sebanyak $500 \mathrm{ml}$, pemberian cairan harus dihentikan sampai perdarahan benar-benar terkontrol. Darah dan komponen terapi harus dihangatkan dan segara diberikan setelah perdarahan terkontrol. Pijat jantung dalam bersamaan dengan administrasi intrakardial epinefrin yang langsung 
disuntikkan ke dalam ruang dari ventrikel kiri dapat dicapai dengan mengangkat keluar jantung untuk memungkinkan visualisasi lebih mudah dari ventrikel kiri. Defibrilasi internal dimulai dengan 20 joule dan dapat ditingkatkan menjadi 40-50 joule.

\section{RINGKASAN}

Keputusan untuk melakukan torakotomi darurat melibatkan penilaian yang cermat terhadap pengetahuan, etika, sosial dan ekonomi. Sebuah manajemen yang cepat dengan Kombinasi kemampuan untuk memprediksi keadaan yang bisa terjadi, kemampuan untuk melihat perubahan tanda-tanda klinis, dan keberanian bedah untuk melakukan prosedur sederhana tapi menyelamatkan nyawa dapat membawa perbedaan besar dalam hasil keluaran untuk pasien bahkan dalam rangkaian sumber daya yang terbatas. Time saving is live saving.

\section{DAFTAR PUSTAKA}

1. American College of Surgeons Committee on Trauma. Thoracic Trauma. In: Advanced Trauma Life Support for Doctors. 6th ed. USA: American College of Surgeons; 1997.p.147-63

2. Cohn SM. Pulmonary Contusion: Review of the clinical entity. J Trauma. $1997 ; 42$ (5):973-9.

3. Kulshreshi P, Munshi I, Wait R. J. Profile of chest trauma in a level 1 trauma centre. $J$ Trauma. 2004 ;57(3):576-81.

4. Woodall N. Fibre-optic intubation including local anaesthesia for awake intubation. Anaesthesia and Intensive Care Medicine 2005; 6 (8) : 273-6

5. Lim E, Goldstraw P. Insertion of a chest tube to drain pneumothorax. Anaesth Intensive Care Med. 2008;9(12):520-2

6. Brasel KJ, Stafford RE, Weigelt JA, Tenquist JE, Borgstrom DC. Treatment of occult pneumothoraces from blunt trauma. J Trauma. 1999 Jun;46(6):987-90; discussion 990-1

7. Parry GW, Morgan WE, Salama FD. Management of haemothorax. Ann R Coll Surg Engl 1996;78:325-326

8. Spodick DH. Acute cardiac tamponade N Engl J Med. 2003;349(7):684-90

9. Rhee PM, Acosta J, Bridgeman A. Survival after emergency department thoracotomy: review of published data from the past 25 years. J Am Coll Surg 2000;190:288-298 